J. Management and Humanity Research

Vol. 4, 2020, 57-76

ISSN: 2582-7766 (online)

Published on 25 January 2021

www.researchmathsci.org

DOI: http://dx.doi.org/10.22457/jmhr.v04a04606

Journal of

\title{
The Impacts of Embeddedness on Competitiveness in Technology Standard-Setting Alliance: From the Perspective of Partner Types and Relations
}

\author{
Saedd Nyasha Kelly \\ School of Management, University of Delaware, Delaware 19716, USA. \\ Email: saeed kelly@gmail.com
}

Received 6 December 2020; accepted 16 January 2021

\begin{abstract}
Based on the new economic sociology theory-embedding theory, this paper analyzes the embedded arrangements among the technology standard-setting alliance' partners, as well as the influence of embedded arrangements on the competitiveness of alliance. First of all, it divides the embeddedness into structural embeddedness and relational embeddedness, and divides the competitiveness of technology standard-setting alliance into technical ability and market ability; Then, this paper probes into the influence of two kinds of embedded arrangements on two kinds of competitiveness, and puts forward the research hypothesis; Finally, it takes verified analysis to the proposed hypothesis using the case of IGRS alliance. There are two new founding. (1) On the relational embeddedness mechanism, from the perspective of partner relations, it needs to build strong ties between partners when the enhancement of alliance technology ability depends on the sharing of tacit technologies between partners. Conversely, weak ties are feasible when partners share explicit technologies. From the perspective of partner types, core R\&D enterprises should maintain strong ties with large and important manufacturers, and maintain weak ties with small manufacturers and minor technology supporting enterprises. (2) On the structural embeddedness mechanism, it is beneficial to improve the capability of alliance competitiveness, if intermediary organizations participate in standard-setting alliance.
\end{abstract}

Keywords: technology standard-setting alliance; structural embeddedness; relational embeddedness; competitiveness

\section{Introduction}

In the era of network economy, standard competition has replaced traditional competition methods such as price competition and brand competition in many industries and has become the most important form of strategic competition. Among the three formation mechanisms of technical standards, that is, the government or standardization organization formulates the standards in a statutory manner, a single company (or a few companies) formulates the standards through private agreements, and the alliance formulates de facto standards and establishes technology through the alliance The standard model is becoming mainstream. According to statistics, there were 301 global 


\section{Saedd Nyasha Kelly}

and influential technical standard alliances in 2005, and more than 450 in 2008 (Aggarwal and Walden, 2009).

For the Standard-setting Alliance, its strategic goal is to establish industry technical standards, and the realization of the goal depends on the competitiveness of the alliance. This article proposes that, different from the previous single-function $R \& D$ alliances and marketing alliances, the fundamental feature of the technical standards alliance is that its competitiveness includes both technical capabilities related to the development of technical standards and market capabilities related to the spread of the standard market. This means that technology The competitiveness of the standards alliance is the sum of the technical capabilities and market capabilities related to standards.

The governance issue among partners is a key factor affecting the competitiveness of the alliance. A sound and complete alliance governance can integrate various capabilities scattered among alliance partners into the overall competitiveness of the alliance, and produce a $" 1+1>2 "$ synergy effect. The governance arrangements of alliances are divided into formal governance and informal governance. Formal governance refers to the management of partnerships with the help of formal contracts, while informal governance is implemented based on informal contract terms such as trust and commitment. The theoretical basis for formal governance of alliances is relatively rich. The mainstream alliance theories such as transaction cost theory and resource dependence theory have conducted a lot of analysis on formal governance and its selection mechanism, while the theoretical basis for informal governance is mainly social capital theory. Discussion on factors such as trust and commitment. This article believes that informal governance is a key issue of the technology standard alliance characterized by knowledge/technology intensiveness. However, there are limitations in current research perspectives on this topic, which are excessively concentrated on the trust mechanism of social capital theory, and the validity of the research conclusions And practicality needs to be improved. Therefore, this article introduces the new economic sociology theory-embedding theory into the informal governance field of alliances, discusses the informal governance arrangements between partners in the technology standard alliance from the perspective of embedded mechanism, and discusses its impact on the competitiveness of the technology standard alliance.

\section{Summary of related research}

The concept of "embedding" was first proposed by Polanyi (1944) in "The Great Change," and its widespread use began when Granovetter (1985) published "Economic Action and Social Structure: Issues of Embeddedness" in the American Journal of Sociology. . The embeddedness view holds that the potential opportunities that the actors may obtain depend on the type of network they are integrated into, and the position of the actors in the network and the relationship they maintain determine whether they can seize these opportunities. The typical analysis framework of embeddedness theory is structural embeddedness and relational embeddedness. Structural embeddedness studies the position of actors in the network, while relational embeddedness studies the strength of the relationship between actors in the network.

Scholars have carried out theoretical and empirical research on the choice of embeddedness and its impact on the organization. These studies can be divided into two perspectives: one is the external perspective, that is, from the perspective of a certain 
The Impacts of Embeddedness on Competitiveness in Technology Standard-Setting Alliance: From the Perspective of Partner Types and Relations

enterprise, discussing the choice of embedded relationship with other organizations, and the impact of different embedding methods on the performance of the enterprise itself. In this regard, scholars agree that the embedded arrangement of organizations and other organizations has a strong impact on their competitiveness, but there are different views on the way of influence, even differences and contradictions. Burt (1992) put forward the view of "structural holes" and analyzed the influence of embedding on network innovation ability from the perspective of network structure. He believed that if actors possess structural holes, they can obtain a lot of information and improve their own technical capabilities; If the main body lacks structural holes, its technological innovation ability will be restricted. Uzzi (1997) and Ostgaard (1996), etc. from the perspective of relational embedding, analyzed the two dimensions of strong and weak ties and proposed that there is a positive correlation between strong ties and firm performance, which can improve the competitiveness of firms. In contrast, Granovetter (1985) and Lin Runhui (2004) believe that weak ties are conducive to the transmission of heterogeneous information, and therefore there is a positive correlation between weak ties and corporate performance, which can also improve corporate competitiveness.

The second is the internal perspective, that is, from the perspective of a certain network organization, discuss the embedded arrangements between members of the network and the impact of different embedded arrangements on the overall network organization. For example, Zhao Hongmei (2002) analyzed the impact of different embedding arrangements on the alliance network effect from the perspective of the alliance as a whole, and concluded that the R\&D alliance network can produce multiple effects, including the knowledge transfer effect and organizational learning related to structural dimensions. Effects, social capital effects and innovation effects related to the relationship dimension, and control effects, information effects and prestige effects related to the location dimension. In Zhao Hongmei's research, the resource endowments of the alliance itself, such as the number of existing patents and innovation capabilities of the $R \& D$ alliance, are not involved. These endowments have an impact on the R\&D effect of the alliance.

It can be seen from the above literature analysis that scholars' research mainly focuses on the embedded arrangements between enterprises and other organizations, and the impact of different embedded arrangements on the enterprises themselves. There is little research on the embedding choices among members of the organization and the impact of different embedding arrangements on the overall organization. As for the special alliance form of the technical standard alliance that this article focuses on, its internal embeddedness and its ability to compete with the alliance Related researches are even rarer in relation to the impact mechanism. Therefore, this article will focus on: discussing the embeddedness of the technical standards alliance and its impact on the competitiveness of the alliance. Specifically, it will study the impact of relational and structural embeddedness on the competitiveness of the technical standard alliance. Competitiveness includes the technical capabilities and market capabilities of the alliance. The research ideas and research path of this article are shown in Figure 1. 


\section{Saedd Nyasha Kelly}

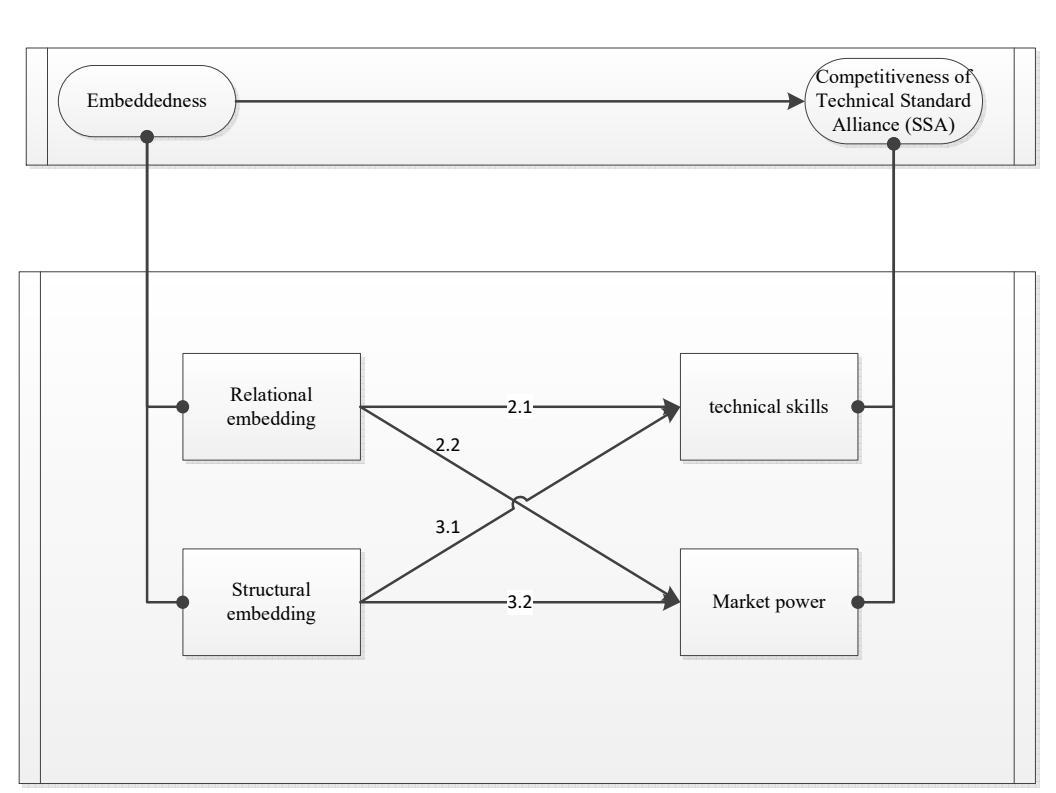

Figure 1: Research concept

\section{The impact of relational embedding on the competitiveness of technical standards alliances}

The concept of relational embedding originated from Granovetter's definition, but Chinese scholars have certain deviations when citing and explaining. Li Ling (2008) believes that relational embedding means that economic actors are embedded in, influenced and determined by their relational network. However, You Daming (2008), Liu Lanjian (2010), and Peng Zhengyin (2001) believe that relational embedding is related to a binary transaction relationship. It refers to the degree to which both parties of a transaction attach importance to each other's needs and goals, and the mutual relationship between the two parties. Degree of trust, trust and information sharing. This article adopts the latter definition.

According to Granovetter's classic classification, relational embedding is divided into two modes: strong relation and weak relation. Among them, strong relationships include four characteristics: high frequency of interaction, strong intimacy, long relationship duration, and homogenization of mutual service content; relatively, the four characteristics of weak relationships are low interaction frequency, weak intimacy, The relationship duration is short and the content of mutual services is heterogeneous. This section uses this classic classification method and characteristic indicators to analyze the impact of relational embedding on the competitiveness of technical standards alliances. The research ideas are shown in Figure 2. 
The Impacts of Embeddedness on Competitiveness in Technology Standard-Setting Alliance: From the Perspective of Partner Types and Relations

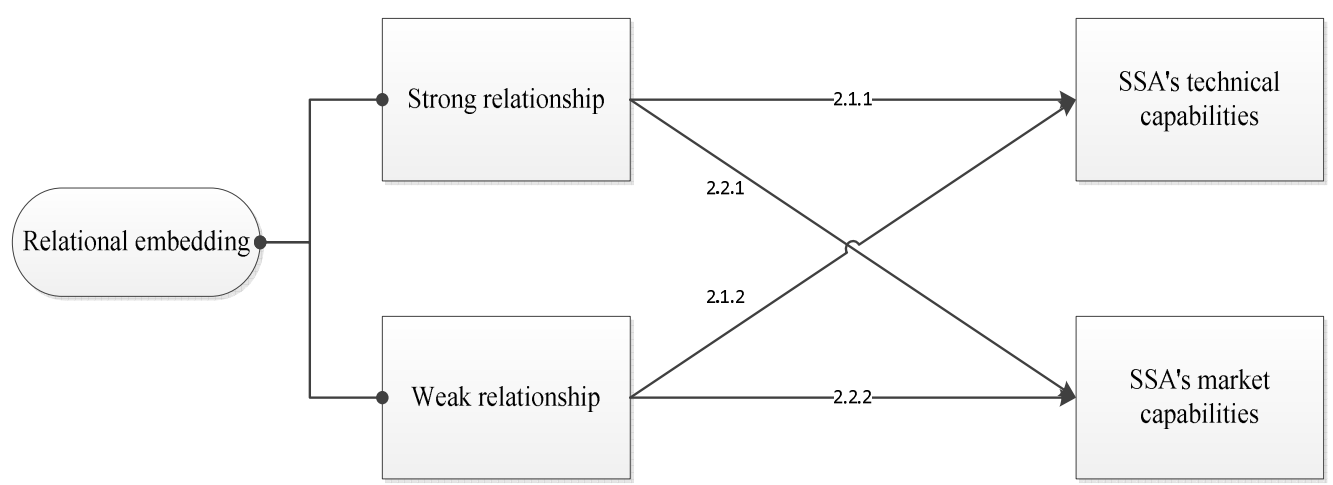

Figure 2: The research idea of relational embedding

\subsection{The impact of relational embedding on the technical capabilities of the technical} standards alliance

The Technical Standard Alliance is a core enterprise that forms a network organization with itself as the core and the goal of standard research and development and market promotion through contact with other alliance members. The technical capability of the Technical Standard Alliance refers to the ability of the alliance to develop and formulate technical standards. From a technical perspective, technical standards usually contain two types of technologies. These two types of technologies are also two sources of technical capabilities: one is explicit existing patented technologies, which can form alliances through mutual authorization and use; The technical know-how and R\&D skills hidden in the member companies can only be substantively promoted for joint R\&D of technical standard sub-modules after they are willing to share with each other and realize the understanding, transformation and absorption, and finally form the technical capabilities of the alliance.

When the technical standards alliance is formed, its technical capabilities exist in two situations: one is that member companies have ready-made patents, and these patents can basically form a technical standard solution; the other is that they do not have all the necessary patents to form a complete technical standard solution, and an alliance is needed. Members cooperate to develop certain patented modules. In the first case, the patents owned by the company are explicit and easy to share and circulate among alliance members; in the second case, the alliance members are required to carry out cooperative R\&D activities. In this case, it is not enough to rely solely on the circulation of patents. Yes, it also requires mutual sharing and transfer of hidden skills, and requires partners to maintain trust in the process of cooperation. Under the above two different resource endowments, the two modes of relational embedding (strong ties and weak ties) in the selection mechanism of technical standards alliance members and their effects are different.

3.1.1. The choice of strong relationship and its impact on the technical capabilities of the technical standards alliance

Scholars have analyzed the positive and negative effects of strong ties. Scholars such as Joel (2010), Ling (2008), Chunyan (2008) believe that there are disadvantages in 


\section{Saedd Nyasha Kelly}

maintaining strong relationships between enterprises. The main point is: strong relationships will lead to information circulation and flow redundancy. With the same information, the chance of obtaining novel information from outside the network will decrease; the maintenance of strong relationships requires a lot of time and energy, that is, more resources are required. Regarding the advantages of strong ties, Ling (2008) believes that strong ties can form mutual trust between enterprises and reduce the risk of opportunism. The reason is that long-term and frequent contacts between enterprises can enable enterprises to understand each other and make more accurate judgments. The cooperative attitude and strength of the other party. Hongmei (2002) analyzes from the perspective of emotions and believes that strong relationships can cultivate mutual emotional bonds and promote trust between enterprises. Rowley (2000), Bian (1997), Liu Lanjian (2010) and other scholars believe that strong relationships provide convenience for the exchange of information between companies, and companies can exchange rich and complex information (hidden skills), which is important for new product development. Has a vital impact.

The previous article discussed two technical capabilities of the Technical Standards Alliance. For the second case, that is, the alliance does not have all the basic patents that form the technical standard program, so members need to share their hidden skills to carry out joint research and development to develop technical modules that are lacking in technology. In order to accomplish this task, $R \& D$ members (often the core technical members of the alliance) need to build effective connections. Because, on the one hand, hidden skills usually involve the core competence of the enterprise, which leads to the low willingness of enterprises to share. In this case, it is difficult to ensure the true sharing of technology only by relying on formal systems (such as signing technology sharing contracts). Therefore, this process can only be realized after mutual trust is established and the cognition of mutual benefit can be realized, and the generation of trust and reciprocal belief requires frequent and satisfactory interaction and contact (that is, the formation of strong relationships between members) In other words, only strong relationships can build an effective incentive environment for the sharing of hidden skills among alliance members. On the other hand, assuming that partners form a willingness to share, the transfer of hidden skills will also face a difficult problem, which is that the skills themselves are not easy to share. Therefore, in order to improve the understanding, transformation and absorption of technology, it is necessary to continue to maintain deep interaction between partners (That is to maintain a strong relationship model), in order to finally realize the substantial sharing of hidden skills and the development of new technologies based on this, thereby enhancing the technical capabilities of the technical standards alliance. Based on the above analysis, hypothesis 1 is proposed.

Hypothesis 1: When the existing patents of the alliance members cannot form a complete technical standard plan, and technical activities characterized by the sharing and transfer of hidden skills are needed, the establishment of strong relationships between technical members is more conducive to the technical capabilities of the technical standards alliance the promotion.

\subsubsection{The choice of weak relationship and its impact on the technical capabilities of the technical standards alliance}

The research on weak ties originated from Granovetter. He believed that weak ties are 
The Impacts of Embeddedness on Competitiveness in Technology Standard-Setting Alliance: From the Perspective of Partner Types and Relations

more conducive to the flow of information than strong ties, that is, weak ties as a bridge can promote the exchange of heterogeneous information between enterprises and maintain the investment of weak ties. Resources are much less than strong relations. Many scholars have verified Granovetter's point of view through research. Bian (1997) conducted a survey on occupational mobility in my country and found that the role of weak ties is mainly reflected in the promotion of information circulation. Subsequently, Van der Aa and Elfring (2002) further proposed that weak ties are more conducive to the exchange of explicit knowledge.

There are two technical conditions in the technical standards alliance mentioned in the previous article. For the first condition, the patented technology owned by the alliance members can basically form a complete solution for the technical standard. At this time, the members only need to mutually authorize each other's patents. Or give up the right to dominate and contribute patents to the alliance, and the technical plan can be completed through patent portfolio packaging. In this process, apart from price negotiations, members do not need to have frequent, in-depth and close interactions, nor do they involve too many technical exchanges, but mainly the authorization and sharing of explicit patents, so between companies Choosing a weak relationship can ensure the implementation of the above behavior. This is consistent with the research conclusions of Van der Aa and Elfring. In addition, maintaining weak relationships with other technology companies can expand the alliance's access to heterogeneous information. For other technology companies in the industry that are not too strong in technology, although their current contribution to technical standards is low, in the long run, keeping in touch with as many such companies as possible will help the alliance to contact and collect more Improve the information of technical standards to ensure the advancement and dynamic upgrading of technical standards. However, in order to control costs, the alliance can maintain a weak relationship model of irregular interaction with these technology companies that may contribute, so as to obtain future contingent technological benefits without increasing resource consumption. Based on the above analysis, hypothesis 2 is proposed.

Hypothesis 2: When the alliance members have all the necessary patents required to formulate technical standards, the R\&D capabilities of the newly joined technology companies are not high (in other words, the alliance companies only need to exchange patents with the core R\&D companies of the alliance), or new In the case where the participating technology companies have relatively weak contributions to technical standards, maintaining a weak relationship between the alliance and such technology companies is more conducive to the improvement of the technical capabilities of the technology standards alliance.

\subsection{The impact of relational embedding on the market capability of the technology standard alliance}

The market capability of the technical standard alliance refers to the ability of upstream and downstream enterprises related to the standard to cooperate with each other to jointly promote the commercialization of technical standards and market diffusion. There are two key nodes in this process. One is the production companies that commercialize technical standards, because they directly face the final consumers, so they have a direct 


\section{Saedd Nyasha Kelly}

impact on the speed of standard marketization. In order to conduct a more in-depth and detailed analysis of the relationship between partners, this article believes that it is necessary to further divide terminal manufacturers into large terminal enterprises and small terminal enterprises. The second is the technology supporting enterprises related to the standard. Because the applications they develop will affect the practicability, ease of use and user experience of the technology, they also have an important impact on the marketization of the standard. Taking the Microsoft operating system as an example, its success in obtaining a de facto standard market position is inseparable from the above two reasons: First, with its superior performance, quality and user experience, terminal companies are generally willing to adopt its standards and large-scale terminal products are listed. It directly promoted the spread of standards among consumers; secondly, Microsoft opened its technology platform to software and application developers for free, and even provided free technical training, which attracted a large number of software development companies to join the technology platform and contributed a lot The application software of Microsoft has further improved the cost-effectiveness of the Microsoft operating system and attracted more consumers to use the standard. This section will specifically analyze the relationship embedding mode between the core R\&D companies in the technology standard alliance and the two types of key node companies.

\subsubsection{The choice of strong relationship and its impact on the market ability of the technical standard alliance}

Since the terminal manufacturer directly faces consumers, his enthusiasm for adopting this standard directly determines the market influence of the technical standard. The transaction cost theory points out that the market-oriented proliferation of every new technology requires corresponding specific asset investment at each node in the industrial chain, and terminal production companies are no exception. In the process of standard formulation and marketization, terminal companies will repeatedly play games with R\&D companies to ensure that the benefits of adopting and promoting the technical standards are greater than the amount of investment in specific assets. As large-scale terminal companies occupy a large market share, if they become users of new technologies, they will directly promote the standardization speed of technology (the Android operating system in the smart phone field is due to the joining of large mobile terminal companies such as HTC and Samsung. Gradually become an important de facto standard). Therefore, when core R\&D companies formulate standards, they need to promptly solicit technical indicators and report parameter levels from major manufacturers to ensure that new technologies can be produced into products and can achieve productization tasks with lower transaction costs. At the same time, large terminal companies should also timely pass on their own technical requirements and production conditions to R\&D companies, maintain the highest coordination and compatibility with each other, reduce unnecessary investment in special assets and weaken market risks. Since this is an iterative process of interaction, only by maintaining a strong relationship, that is, establishing a continuous and intimate relationship, can each other understand the production requirements of technical standards in a timely, accurate and low-cost manner, and realize industrialization, and ultimately promote technology Standard alliance market diffusion capabilities. Based on the above analysis, hypothesis 3 is proposed.

Hypothesis 3: In the technology standard alliance, maintaining a strong relationship 
The Impacts of Embeddedness on Competitiveness in Technology Standard-Setting Alliance: From the Perspective of Partner Types and Relations

between the core R\&D enterprises and large (or important) terminal enterprises is more conducive to the improvement of the technology standard alliance's market capacity.

\subsubsection{The choice of weak relationship and its impact on the market ability of the technical standard alliance}

First, analyze the status of small terminal enterprises in the technology standard alliance and the relational embedding mode determined by it. The characteristics of small terminal enterprises can be summarized as follows: they occupy a small market share, have limited impact on the market, and have a large number. In this case, the core R\&D companies in the alliance and small terminal companies will have the following characteristics when maintaining relationships: (1) Due to the large number of small companies, if they maintain a close relationship one by one, they will inevitably occupy a lot of resources; (2). Because each company's actual production conditions are different, they will have various demands for the production requirements of new technologies. Therefore, R\&D companies cannot meet the demands of all companies when formulating standards, otherwise it will cause serious waste of resources. (3) A single small terminal enterprise has limited influence on the market and has little influence on the marketization of the standard. Its strategy is usually to follow the large terminal enterprise, so the latter should be the strategic key unit. Based on the above analysis, we believe that R\&D companies and small terminal companies are more suitable to maintain a weak relationship characterized by low-frequency interactions and even unilateral actions of core technology companies.

Secondly, analyze the status of technology supporting enterprises in the technology standard alliance and its embedded mode. Technology supporting enterprises mainly develop compatible software and application programs based on the technology standard platform to enhance the practicability of standards. For example, Apple's IOS operating system, in addition to its own advantages, technology supporting companies provide applications based on the IOS operating system (the Apple App Store contains a variety of applications, which greatly satisfy consumers The demand) also promoted the marketization of the IOS operating system. The relationship between technology supporting companies and $R \& D$ companies has the following characteristics: (1) The connection between the two is formed after the emergence of new technologies. The role of technology supporting companies is to supplement local application functions on the basic platform built by technology to enable new technologies. Technology is more easily accepted by consumers; (2) The establishment of the relationship between the two depends on the technology diffusion strategy adopted by the R\&D enterprise, that is, whether the R\&D enterprise as the standard owner adopts a technology standard opening strategy, and whether it allows or attaches importance to peripheral support Enterprises develop supporting technologies on their technology platforms; (3) Technology supporting enterprises have low barriers to entry, so they are numerous. Individuals, small businesses or large enterprises may be involved in the development of application technologies. In summary, the relationship between technology supporting companies and core technology companies is mainly the issue of the right to use the technology standard platform, which is essentially the relationship between authorization and use. Therefore, maintaining a low degree of interaction and intimacy between core $R \& D$ 


\section{Saedd Nyasha Kelly}

companies and technology supporting companies, that is, weak relationships, can meet the needs of rich standard application functions and promote their market proliferation. Based on the above analysis, the following hypothesis 4 is proposed:

Hypothesis 4: In the technology standard alliance, the weak relationship between the core $R \& D$ enterprise and the small terminal enterprise and the technology supporting enterprise can ensure the market diffusion ability of the technical standard.

\section{The impact of structural embedding on the competitiveness of technical standards alliances}

As with relational embedding, the definition of structural embedding also comes from Granovetter, and Chinese scholars further distinguish between macroscopic and microscopic perspectives when quoting. The macro perspective focuses on the overall structure of the network. For example, Daming (2008) believes that structural embedding refers to the overall network structure formed by the interweaving of various relationships (transactional and non-transactional) in the network. Ling (2008) believes that the relationship network formed by actors is embedded in the social structure formed by them and is influenced or determined by cultural and value factors from the social structure. The microscopic point of view focuses on the structural position of a certain node enterprise in the entire network. Zhengyin (2001) believes that structural embededness (structural embededness) can be seen as an extension of the mutual joint contract between groups, which means that organizations not only have bilateral relations, but also have the same relationship with third parties, so that groups can pass through third parties. Connect indirectly and form an association structure characterized by the system. This article uses Zhengyin's micro definition of structural embedding.

The structural hole theory proposed by Burt is a representative theory that analyzes the structural embeddedness of network organizations from the micro level. Burt believes that there are two ways to connect subjects in the network: one is the direct connection between the subjects in the network; the other is that there is no direct connection between the subjects in the network, that is, there is a structural hole between the subjects. According to the theory of transaction costs, a certain amount of resources are required to maintain direct contact between enterprises. If the resources invested in maintaining direct contact are greater than the return obtained, the enterprise will not choose to continue to maintain direct contact. Therefore, there is a limit to the number of companies that can maintain direct contact, and structural holes can expand the scope of corporate communication, that is, through structural holes, companies can get in touch with more third-party companies, communicate with each other, and promote the development of alliance competitiveness. At the same time, enterprises occupying structural holes can obtain more comprehensive information than other enterprises, which is conducive to promoting the development of enterprises themselves, so enterprises will spontaneously generate demand for structural holes. However, in the R\&D partnership of technology standard alliances formed by competitors, is it the optimal arrangement for enterprises to occupy structural holes? This article will use Burt's structural hole theory to compare and analyze the position of structural holes in the technical standards alliance to help improve the competitiveness of the alliance. The research ideas are shown in Figure 3. 
The Impacts of Embeddedness on Competitiveness in Technology Standard-Setting Alliance: From the Perspective of Partner Types and Relations

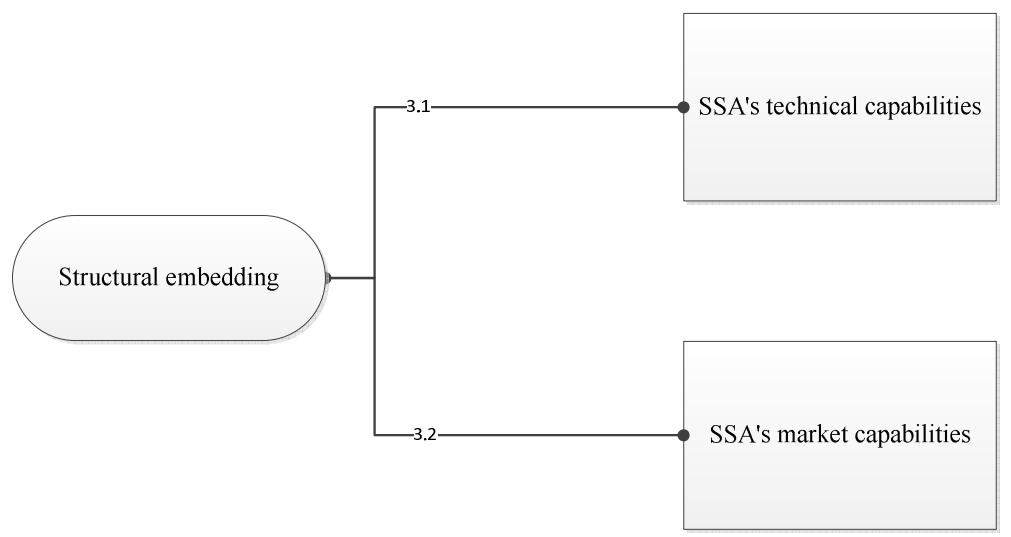

Figure 3: A diagram of research ideas on structural embedding

According to the structural hole theory, the organizations that may occupy the structural hole position in the technical standard alliance are divided into two categories. One is occupied by enterprises, that is, the alliance contains only corporate members; the other is occupied by intermediary agencies, that is, the alliance also contains enterprises. And intermediary organizations. In reality, the membership of the domestic and foreign technical standards alliances can basically be summarized into these two modes. For example, the $3 \mathrm{C}$ and $6 \mathrm{C}$ alliances in the DVD industry belong to alliances that only contain corporate members, while the MPEG alliance has a professional intermediary agency MPEG-LA, and the IGRS alliance and the AVS alliance also have professional intermediary agencies.

\subsection{The impact of structural embedding on the technical capabilities of the technical standards alliance}

As mentioned above, the technical capabilities of the Technical Standards Alliance is reflected in the R\&D capabilities of R\&D companies in the alliance for technical standards. Therefore, the following mainly analyzes the structural embedded arrangements between $\mathrm{R} \& \mathrm{D}$ companies in the technical standard alliance and its impact on the technical capabilities of the technical standard alliance.

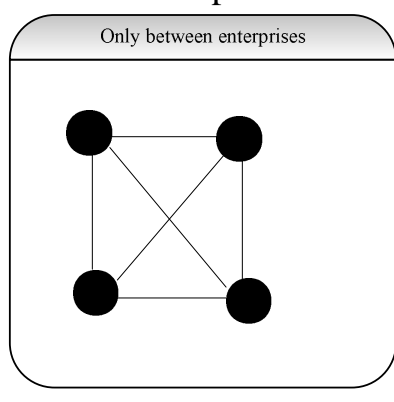

4(a)

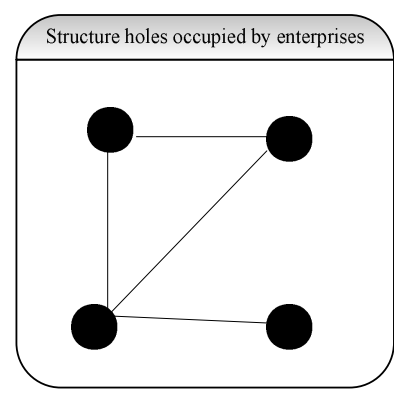

$4(\mathrm{~b})$

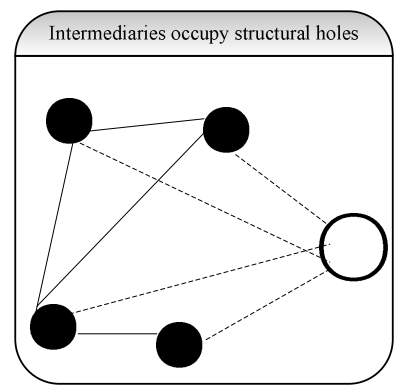

4 (c)

Figure 4: Schematic diagram of the technical capabilities of the Technical Standards Alliance 
The R\&D companies in the Technical Standards Alliance have the same goal, which is to promote the development of technical standards, but as homogeneous companies, there is a competitive relationship between them, so they will not actively and completely transmit information, that is, there is a weakening effect. This weakening effect can be described by the algorithm used by Yongzhou (2009) when analyzing knowledge flow. This article measures the technical capabilities of the alliance by the effect of each company's unique technical capabilities (technical capabilities that other companies do not possess) in the alliance. Assuming that the unique technological capability of each enterprise is 1 , if a direct connection is established between enterprises, the unique technological capability of the enterprise will not be weakened during transmission, but will be directly superimposed, as shown in Figure 4(a). The technical capability of the alliance is 16. However, since direct contact takes up a lot of resources, the number of direct contacts is limited, and structural holes need to be constructed. If the structural hole is occupied by the enterprise, then the unique technological capability is weakened in the transmission, assuming that the weakening coefficient is $\mathrm{i}(0<\mathrm{i}<1)$. After transmission, as shown in Figure 4(b), the technical capability of the Technical Standard Alliance is $12+4 \mathrm{i}$. In order to reduce the weakening effect produced in the above-mentioned technology transfer process, you can try to replace the enterprise with an intermediary structure as a structural hole and play a synergistic function. First, intermediary agencies can ease the competitive relationship between enterprises and promote cooperation among homogeneous enterprises within the alliance. Professional intermediary structures such as industry associations are responsible for communicating and managing related enterprises, and most of their energy and resources are also invested in Secondly, the intermediary agencies gather most of the information in related industries and have experts in various fields, so they can make comprehensive and professional analysis of related fields; while the intermediary agencies absorb and transform relevant information, they can also inform the enterprise Deliver more comprehensive information. Therefore, this article believes that intermediaries can strengthen the transfer of technological capabilities between enterprises in the alliance, and its strengthening coefficient is $\mathrm{k}(\mathrm{k}>$ 1 ), as shown in Figure 4(c). At this time, the technical capability of the alliance is $12+4 \mathrm{k}$. Since $k>1>i,(12+4 k)>(12+4 i)$, the technical capability of alliances with intermediaries is greater than that without intermediaries. In reality, there are intermediaries in many technical standard alliances. For example, at the beginning of its establishment, the IGRS Technical Standards Alliance established the IGRS Standards Working Group, and then the Beijing IGRS Information Industry Association; the AVS Technical Standards Alliance also established the AVS Standards Working Group at the beginning of its establishment. Based on the above analysis, hypothesis 5 is proposed.

Hypothesis 5: Compared with an alliance structure that only includes corporate members, the existence of an intermediary organization in the technical standards alliance is more conducive to the improvement of the alliance's technical capabilities.

\subsection{The impact of structural embedding on the market capability of the technology standard alliance}

The impact of structural embedding on the market capability of the technology standard alliance comes from two aspects: one is the market power caused by the overall scale, 
The Impacts of Embeddedness on Competitiveness in Technology Standard-Setting Alliance: From the Perspective of Partner Types and Relations

that is, the more members, the larger the overall scale of the technology standard alliance, and its market influence. The second is the connection method between alliance members, especially the vertical cooperation relationship formed by the upstream and downstream enterprises of the industrial chain, which has an important decisive role in the industrialization of technical standards and market diffusion, which means that the vertical enterprises within the alliance Structural embedded arrangements have a greater impact on the alliance's market capabilities. Consistent with the context of the previous analysis, the structural embedding arrangements of R\&D companies with downstream terminal companies and upstream technology supporting companies are discussed below.

\subsubsection{There is only direct contact between enterprises}

With the advancement of technology, standards have become more and more complex. At the same time, the number of patents included in the standards has also increased, making it difficult for a single company to own all the patents included in the standard. Therefore, whether it is a terminal enterprise or a technology supporting enterprise, when using the standard, it needs to obtain a large number of $R \& D$ enterprise authorizations (as shown in Figure 5). This has the following disadvantages: (1) In the process of marketization of technology standards, a large number of negotiations between R\&D companies, production companies and assistive technology development companies need to be carried out, which in turn generates excessive transaction costs, consumes excessive resources, and may delay the development of new technologies. Marketization process. As shown in Figure 5, each terminal company needs to contact three R\&D companies to obtain related patents, and each R\&D company needs to contact six companies (including three terminal companies and three auxiliary technology development companies); (2) It is easy to cause conflicts between enterprises. Since R\&D companies have the core resource of the alliance - standards, and other companies must obtain authorization to use the standards when developing related products based on standards. This easily leads to R\&D companies "sit on the floor" and increase the burden on other companies; at the same time, when using When the cost rises to a certain level, terminal companies and assistive technology development companies will avoid adopting the technology, which will lead to a reduction in the standard market share. Once a vicious circle is formed, it is very unfavorable to the market proliferation of new technology standards.

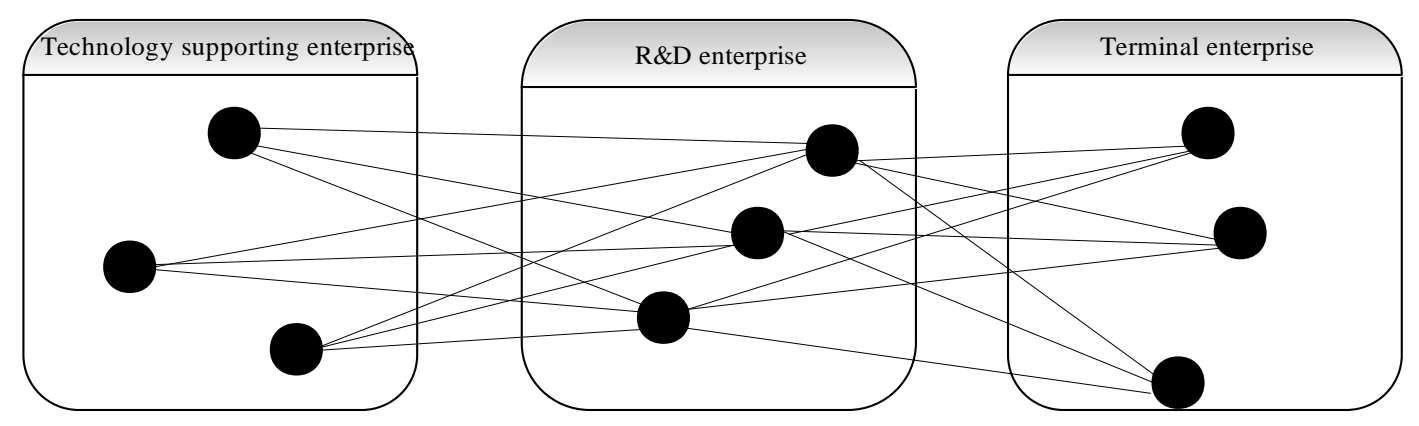

Figure 5: Direct contact between R\&D companies and other companies 


\section{Saedd Nyasha Kelly}

\subsubsection{The situation where intermediaries occupy structural holes}

The existence of structural holes helps the network to strengthen its information acquisition capabilities. So, what role does the introduction of intermediary institutions have as structural holes in the technical standards alliance? Gao Lina (2011) believes that intermediary agencies not only promote mutual exchanges between various organizations, but also provide professional services such as innovative resource allocation, innovative decision-making and management consulting, thereby accelerating the marketization of scientific and technological achievements. Therefore, it is reasonable to speculate that intermediary agencies (such as professional third-party patent management companies) participating in the technical standards alliance will help accelerate the market diffusion of technical standards. In reality, intermediary agencies often understand market needs and trends better than R\&D companies, and better understand the technical content of standards and the various resources needed to develop standards than terminal companies and assistive technology development companies. Moreover, intermediary agencies can also stand on the whole The industry's perspective analyzes the technological advancement of standards and the level of market demand. Therefore, intermediary agencies can provide $\mathrm{R} \& \mathrm{D}$ companies, terminal companies, and assistive technology development companies with information they lack so that they can fully analyze the market. In addition, intermediary agencies can also play a coordinating function in the technical standard alliance, which can connect the upstream and downstream of the technical standard industry chain to transfer each other's needs, promote the mutual cooperation of various enterprises in the technical standard alliance, and reduce the cooperation between the members Consumed resources in turn enable technical standards to be industrialized at a lower cost and faster speed. Based on the above analysis, hypothesis 6 is proposed.

Hypothesis 6: Compared with the structure where there are only corporate members, when there are intermediaries occupying structural holes in the technical standards alliance, it is more helpful to enhance the alliance's market capabilities and accelerate the market diffusion of technical standards.

\section{Case study-embeddedness in IGRS industry technology standard alliance}

IGRS Industrial Technology Standards Alliance (hereinafter referred to as "IGRS") was established in 2003, focusing on the research and development and promotion of intelligent interconnection technology for home appliances, and is a relatively mature industrial alliance in my country. "IGRS" consists of two parts: "IGRS" Information Industry Association (referred to as the Association) and "IGRS" Information Technology Engineering Center (referred to as Technical Engineering Center). The former is mainly responsible for the formulation of standards and the daily work of the alliance, and the latter Mainly responsible for the industrialization and market promotion of IGRS technology. The members of the association are divided into four categories: core members, promotion members, ordinary members and observation members. The core members include 14 companies including Lenovo, TCL, Great Wall, Changhong, Skyworth, Hisense, Konka, Zhonghewei, China Electronics Standardization Institute, Netcom, Huawei, Midea, IGRS Information Technology Engineering Center, and Hong Kong Applied Science and Technology Research Institute. The other three types of members total about 140. The Technical Engineering Center is jointly established by the 
The Impacts of Embeddedness on Competitiveness in Technology Standard-Setting Alliance: From the Perspective of Partner Types and Relations

8 core members of the "IGRS" Information Industry Association (that is, the first 8 of the 14 core units mentioned above). The following is a detailed analysis of the embedded arrangements among the members of the IGRS alliance.

\subsection{Relational embedding in IGRS}

(1) Between technical members

On the one hand, the core R\&D companies of IGRS have built and maintained strong relationships (confirming Hypothesis 1). The core members of the association are leading companies in the $3 \mathrm{C}$ industry and are the initiators of the alliance. At the same time, they are also the main research and development units of technical standards. As core members, they not only proposed the initiative to initiate the technical standard, formulated the basic functions and composition of the technical standard, respectively undertook the substantive research and development work of the relevant standard working group, participated in the alliance's membership meeting, and also held regular Core member meeting to exchange and discuss standard research and development work. On the other hand, the remaining three types of members, including ordinary members, maintain weak relationships (confirming Hypothesis 2). Both in terms of communication frequency and depth of interaction, they have obvious communication with each other and with core members. cut back.

The above-mentioned characteristics of partnership constructed in IGRS can be explained from the perspective of strong/weak relationship theory, which is also consistent with the relevant theories and research hypotheses made by the author in the previous article. First of all, in terms of core member relationship construction, "IGRS" was initiated and established by Lenovo Group. At the time of initiation, the alliance company did not own all the patents that formed the "IGRS" technical standards, so it was necessary to select partners to carry out joint research and development, except for sharing In addition to the explicit technology patents that partners already own, more importantly, key decisions are negotiated on technical composition, module cutting and integration, compatibility and interconnection, and this process usually involves a large number of tacit knowledge sharing activities. In this process, the core R\&D partners of "IGRS" chose to establish strong relationships with each other. In theory, the strong relationship model can provide partners with an efficient interactive platform, enabling high-frequency and deep communication and coordination. The transfer of invisible knowledge is realized and efficient, ensuring that complex technical standard programs can be established at the fastest speed. For the embedded model of ordinary R\&D companies, due to the weak R\&D strength of such companies, the resource input and ability sharing of technical standards are limited. Therefore, there will be no intensive interaction and coordination between core R\&D companies and such companies, so there is no need to spend more resources and costs to maintain strong relationships with them. Building weak relationships can form communication channels, achieve necessary communication, and Obtain the contribution that such companies can make to the establishment of technical standards.

\section{(2) Between technical members and industrialized members}

On the one hand, the core R\&D companies in IGRS maintain a strong relationship with 


\section{Saedd Nyasha Kelly}

large terminal companies (which confirms Hypothesis 3). The performance is: in the technical engineering center responsible for the industrialization and market promotion of IGRS standards, all of the eight co-construction units (ie core members) have production functions. On the other hand, core R\&D companies and small-scale production companies and technology supporting companies mainly maintain weak relationships (confirming Hypothesis 4). The performance is: the alliance helps enterprises to quickly develop products such as IGRS high-definition televisions and web players through the IGRS middleware platform.

The above embedded arrangement can be explained in the strong/weak relationship theory. First of all, the author found that the large terminal enterprises in "IGRS", in addition to production functions, often also have R\&D functions at the same time, which is likely to be the root cause of the strong relationship arrangement. For example, in the technical engineering center responsible for the production and marketing of IGRS standards, all eight co-construction units are core members of the alliance that simultaneously undertake the two functions of core technology research and development and production. These core members not only determine the technical solutions of the "IGRS" standard, but also assume the functions of industrialization. This will inevitably lead to frequent and close ties between each other in the R\&D, production and marketing links. Therefore, only the construction of strong The relationship model can meet the above interactive needs. Therefore, the "IGRS" R\&D companies maintain a strong relationship with large terminal companies. The following theoretical predictions may be made here. Even if large-scale production companies only undertake a single production intelligence, core $R \& D$ companies will maintain a strong relationship with them, because only in this way can the standard efficient production and rapid occupation of the market be guaranteed. Secondly, the process of industrialization of IGRS technology involves a large number of small production enterprises and technology supporting enterprises. Although they have an important influence on the industrialization of IGRS technology standards as a whole, from the perspective of individual enterprises, the decision of each enterprise is The effects are relatively small, and there are compatibility and synergy problems caused by differences in operating systems, processors, and application systems among enterprises. Therefore, maintaining a strong relationship between core R\&D companies and them will significantly increase transaction costs in the process of industrialization. In order to avoid this drawback, IGRS Alliance has adopted a connection model that maintains an indirect relationship with small businesses, that is, develops IGRS middleware platforms and licenses them to enterprises for a fee. All IGRS supporting technology and terminal product manufacturers directly operate on the middleware platform, without having to maintain a strong relationship with core $R \& D$ companies with high frequency of communication, and reduce the communication links between enterprises, thereby reducing collaboration costs. Therefore, we have reason to believe that maintaining a weak relationship between core R\&D companies and small terminal companies and technology supporting companies can meet the needs of the alliance.

\subsection{Structural embeddedness in "IGRS"}

The "IGRS" alliance includes two intermediary organizations-IGRS Information Industry Association and IGRS Information Technology Engineering Center, which occupy the 
The Impacts of Embeddedness on Competitiveness in Technology Standard-Setting Alliance: From the Perspective of Partner Types and Relations

key node positions of R\&D enterprise groups and terminal enterprise groups within the alliance respectively. Among them, IGRS Information Industry Association is responsible for the formulation of IGRS standards (which confirms Hypothesis 5), and the IGRS Information Technology Engineering Center is responsible for the market promotion of IGRS standards (which confirms Hypothesis 6).

The structural embedded arrangement of IGRS is consistent with the relevant theories and research hypotheses discussed by the author in the previous article. In terms of standard formulation, the IGRS Information Industry Association, as an intermediary structure, occupies the key node of the $R \& D$ member group and functions as a coordinator. The association contains more than 140 companies, each of which belongs to one or more standard research and development teams, contributing to the technical capabilities of the company, and participating in the co-construction of technical standards in the form of independent research and development or cooperative research and development. However, these R\&D teams deploy and implement related R\&D work under the overall leadership of the Association. The association divides labor according to the technical advantages of each enterprise, and provides a platform for technical exchanges between enterprises, sharing related technologies, and overall planning of standard research and development. The association can not only collect all kinds of R\&D information, but also pass it to the enterprise after a certain absorption and transformation, thereby generating an incremental effect of technological capabilities. In addition, the association as an intermediary can also significantly save transaction costs in the process of standard research and development. $R \& D$ companies can reduce mutual contacts and unify the contact with the association, that is, change from a network structure to a star structure, and the association is in a star structure. This can greatly save the cost of transferring information between enterprises. In terms of marketing promotion, the technical engineering center is mainly responsible. It occupies the key node of the terminal enterprise group. It can not only strengthen communication with $R \& D$ enterprises as a representative of the terminal enterprise, and strengthen the operability of standard marketing promotion, but also provide a platform for the transmission of information between terminal enterprises and strengthen mutual communication. . Its eight co-construction units are both terminal enterprises and technical standards research and development enterprises, and they have advantages in promoting the coordination of standards and terminal products. The Engineering Center is responsible for the unified external authorization of IGRS standards, and is also responsible for the research and development of supporting technologies that help promote the practical application of the standards. This can not only avoid standard multi-head authorization and reduce the efficiency of terminal enterprises, but also reduce the resources consumed by terminal enterprises in adopting standards.

\section{Conclusion}

From the perspective of typical partner types and relationships in technical standards alliances, this paper conducts a theoretical analysis of the embedded arrangements in technical standards alliances, and specifically discusses the impact of embeddedness on the competitiveness of technical standards alliances (the embeddedness is divided into structural embeddedness). Competitiveness is divided into R\&D capability and market 


\section{Saedd Nyasha Kelly}

capability), and six research hypotheses are proposed. Aiming at the research hypothesis, the thesis conducted a case analysis of the IGRS Industry Technical Standards Alliance, and found that the theoretical hypothesis was basically consistent with the IGRS realistic management model, so the theoretical analysis of this article was supported by typical cases. The main findings of this paper can be summarized as Figure 6 below.

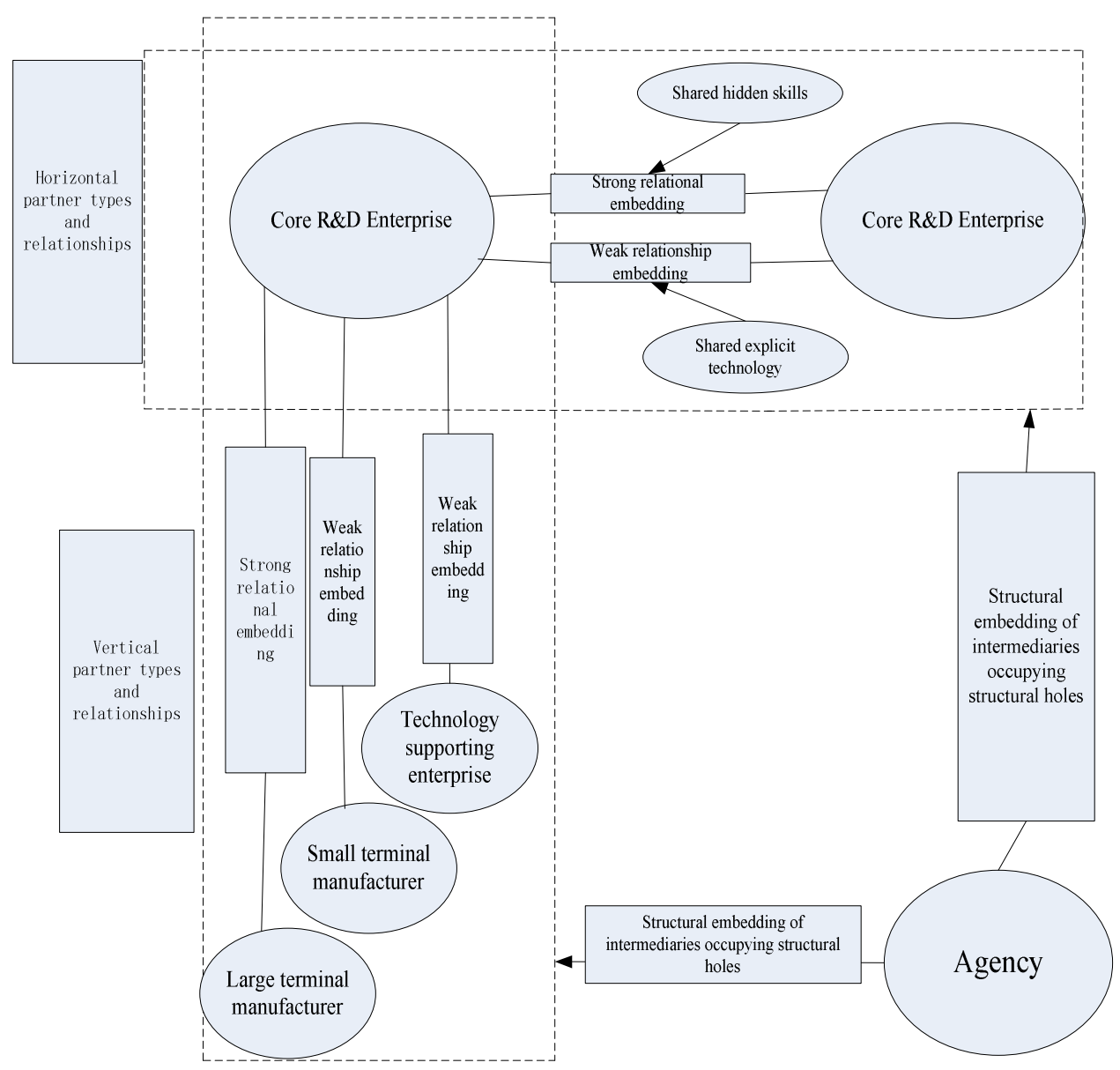

Figure 6: The embedded arrangement in the technical standards alliance

In terms of relational embedding arrangements and their effects, this article finds: (1) Between core technology companies, both strong and weak ties can improve the overall technical capabilities of the alliance to a certain extent, but the alliance needs to be based on its own resources. Choose different relational embedding arrangements. If the technical standards alliance lacks patent support and needs to strengthen the follow-up $R \& D$ strength of the alliance members, then R\&D companies need to maintain a strong relationship. A strong relationship can promote the transfer of hidden skills among alliance members, thereby promoting the development of alliance technical capabilities. However, a strong relationship has a drawback, that is, more resources need to be invested, which can only promote the transfer of hidden skills among partners within a 
The Impacts of Embeddedness on Competitiveness in Technology Standard-Setting Alliance: From the Perspective of Partner Types and Relations

certain range. If the technical standards alliance has enough patents and does not require high requirements for the alliance's subsequent $R \& D$ strength, it is more appropriate to maintain weak relationships among R\&D companies. As an explicit technical capability, the main method of circulation of patents is mutual authorization. Alliance members do not need to maintain strong relationships that consume more resources, but only weak relationships. In addition, maintaining weak relations between alliance members can expand the scope of exchanges and promote the circulation of patents on a larger scale. (2) Different relational embedding arrangements should be selected according to different situations between core technology enterprises and other industrial chain enterprises. Core R\&D companies and large terminal companies should maintain a strong relationship to promote the two parties' repeated gaming process, mutual information can be more comprehensively transmitted to each other to promote the development of standards; core R\&D companies and small terminal companies can choose to maintain a weak relationship. Reduce relationship maintenance costs without affecting the industrialization of technology, and provide resource guarantees for the development of core technologies; R\&D enterprises and secondary technology supporting enterprises are also suitable to establish weak relationships, which will not affect the implementation of the technology authorization process and the completion of compatible supporting technologies The development of this technology is also conducive to obtaining complementary information from these heterogeneous companies to improve the performance and quality of technical standards.

In terms of structural embedding arrangements and their effects, this article finds that, compared to structures that only contain corporate members, third-party intermediaries joining the technical standards alliance can promote the improvement of alliance competitiveness (including technical and market capabilities). (1) In terms of promoting the development of technological capabilities, intermediary agencies can coordinate R\&D enterprises within the alliance. Due to the limited resources of enterprises, it is difficult for R\&D companies to directly communicate with each other. The more common situation is to communicate with each other through a third party. As a third party, intermediary agencies can expand the depth and breadth of the transfer of technical capabilities, thereby promoting the development of technical capabilities. (2) In promoting the development of market capabilities, intermediary agencies can coordinate R\&D companies with terminal companies and technology supporting companies. Each node enterprise in the standard industry chain is connected to promote the development of standards, which requires a lot of resources, and intermediary agencies can reduce the consumption of resources. At the same time, from the perspective of the entire industry, intermediary agencies judge the technological advancement of the standard and the level of market demand, which can promote the standard to be more practical.

The above theoretical analysis and findings in this article can provide certain experience for enterprises to organize and participate in technical standards alliances, and provide theoretical references for promoting domestic technological innovation and technical standards strategy. Regarding the embedding arrangement in the technical standards alliance, the author believes that the network structure analysis method can be further used for quantitative research, and the embedding mechanism can be dig deeper. 


\section{Saedd Nyasha Kelly}

\section{REFERENCES}

1. N.Aggarwal and E.A.Walden, Intellectual Property Bundle (IPB) theory: Managing transaction costs in technology development through network governance, Decision Support Systems, 48 (2009) 23-32.

2. K.Polanyi, The Great Transformation: The Political and Economic Origins of Our Time, Boston, MA: Beacon Press, 1944.

3. M.Granovetter, Economic action and social structure: the problem of embeddedness, American Journal of Sociology, 91(3) (1985) 481-510.

4. R.S.Burt, Structural Holes: The Social Structure of Competition, Cambridge, MA: Harvard University Press, 1992.

5. B.Uzzi, Social structure and competition in interfirm networks: the paradox of embeddedness, Administrative Science Quarterly, 42(1) (1997) 35-67.

6. T.A.Ostgaard and S.Birley, New venture growth and personal networks, The Journal of Product Innovation Management, 13(6) (1996) 557-558.

7. L.Runhui, Network organization and high growth of enterprises, Tianjin: Nankai University Press, 2004.

8. Z.Hongmei. Research on the formation mechanism of R\&D alliance network effect from the perspective of social network, Science of Science and Management of Science and Technology, 8 (2002) 22-27.

9. L.Ling, Research on the influence of network embeddedness on the effective acquisition of knowledge, Science of Science and Management of Science and Technology, 12 (2008) 97-100.

10. Y.Mingda, Research on enterprise integrated innovation model and dynamic decision model from the embedded perspective, Statistics and Decision, 7 (2008)33-35.

11. L.Lanjian, Network embeddedness: basic research questions and framework, Science and Technology Progress and Policy, 13 (2010) 153-160.

12. P.Zhengyin, Network governance: governance theory based on network morphology, China Economics Annual Conference, Beijing, 2001.

13. A.C.Joel and R.Cowan, Network-independent partner selection and the evolution of innovation network, Management Science, 56(11) (2010) 2094-2110.

14. J.Chunyan, Organizational learning, social capital and corporate entrepreneurship-an empirical study of emerging enterprises in jiangsu and Guangdong, Journal of Management Science, 6 (2008) 61-76.

15. T.Rowley, D.Behrens and D.Krackhardt, Redundant governance structures: an analysis of structural and relational embeddedness in the steel and semiconductor industries, Strategic Management Journal, 21(3) (2000) 369-386.

16. Y.Bian, Bringing strong ties back in: Indirect ties, network bridges, and job searches in China, American Sociological Review, 6(62) (1997) 366-385.

17. Van der Aa W., T.Elfring, Realizing innovation in services, Scandinavian Journal of Management, 2 (2002) 155-171.

18. L.Yongzhou, The knowledge flow structure of network organization and the agglomeration and innovation mechanism of national high-tech zones, China Soft Science, 5 (2009) 89-95.

19. G.Lina, The impact of the heterogeneity of science and technology intermediary institutions on regional innovation capabilities, Forum on Science and Technology in China, 5 (2011) 86-90. 